\title{
Research
}

\section{Severity of impacts of an introduced species corresponds with regional eco-evolutionary experience}

\author{
Kimberley T. Davis, Ragan M. Callaway, Alex Fajardo, Aníbal Pauchard, Martin A. Nuñez, Rob W. Brooker, \\ Bruce D. Maxwell, Romina D. Dimarco, Duane A. Peltzer, Bill Mason, Seppo Ruotsalainen, \\ Anne C. S. McIntosh, Robin J. Pakeman, Alyssa Laney Smith and Michael J. Gundale
}

K. T. Davis (http://orcid.org/0000-0001-9727-374X) (kimberley.davis@umontana.edu), Dept of Ecosystem and Conservation Sciences, Univ. of Montana, Missoula, MT, USA. - R. M. Callaway, Division of Biological Sciences, Univ. of Montana, Missoula, MT USA. RMC also at: Inst. on Ecosystems, Univ. of Montana, Missoula, MT, USA. - A. Fajardo (http://orcid.org/0000-0002-2202-6207), Centro de Investigación en Ecosistemas de la Patagonia (CIEP) Conicyt-Regional R10C1003, Univ. Austral de Chile, Coyhaique, Chile. - A. Pauchard, Laboratorio de Invasiones Biológicas (LIB), Facultad de Ciencias Forestales, Univ. de Concepción, Concepción, Chile. AP also at: Inst. of Ecology and Biodiversity (IEB), Las Palmeras, Santiago, Chile. - M. A. Nuñez, Grupo de Ecologia de Invasiones, INIBIOMA, CONICET, Univ. Nacional del Comahue, San Carlos de Bariloche, Argentina. - R. W. Brooker and R. J. Pakeman, The James Hutton Inst., Craigiebuckler, Aberdeen, UK. - B. D. Maxwell, Land Resources and Environmental Sciences Dept, Montana State Univ., Bozeman, MT, USA. - R. D. Dimarco, Grupo de Ecología de Poblaciones de Insectos, INTA EEA Bariloche, CONICET, San Carlos de Bariloche, Argentina. - D. A. Peltzer (http:/lorcid.org/0000-0001-7724-3738), Landcare Research, Lincoln, Canterbury, New Zealand. - B. Mason, Forest Research, Northern Research Station, Roslin, Midlothian, UK. - S. Ruotsalainen, Punkaharju Research Unit, Natural Resources Inst. Finland (Luke), Punkaharju, Finland. - A. C. S. McIntosh, Dept of Science, Augustana Campus, Univ. of Alberta, Camrose, AB, Canada. - A. Laney Smith, Dept of Ecology and Evolutionary Biology, Univ. of Arizona, Tucson, AZ, USA. - M. J. Gundale, Dept of Forest Ecology and Management, Swedish Univ. of Agricultural Sciences, Umeå, Sweden.

\section{Ecography}

42: 12-22, 2019

doi: $10.1111 /$ ecog.04014

Subject Editor: Bethany Bradley Editor-in-Chief: Miguel Araújo Accepted 12 September 2018
Invasive plant impacts vary widely across introduced ranges. We tested the hypothesis that differences in the eco-evolutionary experience of native communities with the invader correspond with the impacts of invasive species on native vegetation, with impacts increasing with ecological novelty. We compared plant species richness and composition beneath Pinus contorta to that in adjacent vegetation and other $P$. contorta stands across a network of sites in its native (Canada and USA) and nonnative (Argentina, Chile, Finland, New Zealand, Scotland, Sweden) ranges. At sites in North America and Europe, within the natural distribution of the genus Pinus, P. contorta was not associated with decreases in diversity. In the Southern Hemisphere, where there are no native Pinaceae, plant communities beneath $P$. contorta were less diverse than in other regions and compared to uninvaded native vegetation. Effects on native vegetation were particularly pronounced where $P$. contorta was a more novel life form and exhibited higher growth rates. Our results support the hypothesis that the eco-evolutionary experience of the native vegetation, and thus the novelty of the invader, determines the magnitude of invader impacts on native communities. Understanding the eco-evolutionary context of invasions will help to better understand and predict where invasion impacts will be greatest and to prioritize invasive species management.

Keywords: biological invasion, biodiversity, eco-evolutionary experience 


\section{Introduction}

Many theories in invasion biology implicitly stem from the idea that the success or impact of biological invaders are determined by their evolutionary or functional novelty, and this depends on the naïveté of the invaded community (e.g. enemy release, novel weapons, evolution of increased competitive ability; Daehler 2001, Keane and Crawley 2002, Callaway and Ridenour 2004, Hierro et al. 2005, Saul et al. 2013). This idea was first proposed by Darwin, who suggested that plant species introduced across biogeographic barriers into habitats with congeneric natives would be less likely to succeed than they would be in habitats without congeners. The rationale for this was that congeners may be more likely to compete for similar resources or sustain consumers with congeneric preferences (Darwin's naturalization hypothesis; Darwin 1859, Daehler 2001). Darwin's naturalization hypothesis has been widely tested with mixed results depending on spatial scale and invasion stage (Rejmánek 1996, Daehler 2001, Duncan and Williams 2002, Diez et al. 2008, Proches et al. 2008). More recently, the term 'eco-evolutionary experience' was introduced to overcome shortcomings with predictions based solely on phylogenetic novelty. The term has further shifted the focus to the experience that species gain in their native range by adapting to biotic interactions over evolutionary time (Saul et al. 2013). Despite the logical extension from invasion success to invasion impact, the importance of eco-evolutionary experience in determining the severity of invasion impacts across sites remains largely unknown (but see Ricciardi and Atkinson 2004). Within sites, phylogenetic relatedness to the invader has partially explained variability in impacts on individual species (Bennett et al. 2014, Li et al. 2015), but to our knowledge no study has quantified the community-level impacts of an invader across introduced ranges that also vary in evolutionary history with the genus or family of that invader. Invasion impacts are known to vary largely across non-native ranges (Pyšek et al. 2012, Hulme et al. 2013, Kumschick et al. 2015), and eco-evolutionary experience is likely to be an important but poorly understood driver of this variation in impacts (Saul and Jeschke 2015).

The impacts of invaders are context specific (Vilà et al. 2006) and large-scale biogeographic differences in invader impacts on local biodiversity have been found between species' native and introduced ranges (Callaway et al. 2012, Shah et al. 2014, Ledger et al. 2015, Hejda et al. 2017, Brewer et al. 2018). Hypotheses for differences in invader impacts between native and non-native ranges include increased resource competition due to greater size of the invaders in the non-native range, novel effects on nutrient cycling, and different evolutionary histories in biochemical processes (Callaway and Aschehoug 2000, Ni et al. 2010, Kaur et al. 2012, Qin et al. 2013). These mechanisms may explain why, within a non-native range, a non-native species might have greater impacts where it is functionally or phylogenetically different than dominant native species (Levine et al. 2003). Consistent with this, a meta-analysis of 113 non-native plant species found that those that differed the most in functional traits from native species were more likely to alter soil $\mathrm{N}$ pools (Castro-Diez et al. 2014). Similarly, interactions between soil microbial communities and non-native pine species depend on the history of coexistence between the native biota and species functionally similar to the introduced pines (Gazol et al. 2016, Gundale et al. 2016). For example, ectomycorrhizal pines are more likely to alter native soil biota where no native ectomycorrhizal species occur than where native ectomycorrhizal species exist (Nuñez and Dickie 2014, Gazol et al. 2016). Therefore, we expect introduced plants to have more severe impacts on natives in environments where they are more taxonomically and functionally different than natives, than in environments where the invader is taxonomically and functionally similar to dominant native species and thus native species have acquired eco-evolutionary experience interacting with similar species.

In order to test whether eco-evolutionary experience affects the impact of an exotic species, we used a global network of forest stands of the commercially-important tree species Pinus contorta (Douglas ex Loud.), which has a wide climatic and geographical range. The network includes stands in its native range (Canada and USA) and in two regions outside of its native range, one (Europe) where congeneric species occur and one (Southern Hemisphere) where congeners, or members of the same family, do not occur naturally (Engelmark et al. 2001, Simberloff et al. 2010, Gundale et al. 2016, Taylor et al. 2016a). Pinus (pine) introductions have been suggested as ideal systems for testing whether the impacts of exotic species vary due to biogeographical factors (Gundale et al. 2014b), because the genus is made up of species whose natural distribution is almost entirely restricted to the Northern Hemisphere (Rundel et al. 2014). This is the result of evolutionary divergence in the Coniferophyta after the separation of Laurasia and Gondwana roughly 200-250 myr BP (Leslie et al. 2012). In the last 150 yr, many Pinus species, including $P$. contorta, have been moved by humans beyond this biogeographical limit. Millions of hectares have been planted in the Southern Hemisphere, originally to reduce mountain soil erosion, and then as the foundation of production forestry (Simberloff et al. 2010, Nuñez et al. 2017). Pinus contorta (as well as other North American Pinaceae) has also been introduced to Europe, where many other members of the Pinaceae are native. Pinus contorta is one of the most invasive species of Pinus in the Southern Hemisphere and has been classified as naturalized or invasive in several European countries (Langdon et al. 2010, Simberloff et al. 2010, Rejmánek and Richardson 2013). Pinus contorta can have significant impacts on the ecosystems where it invades, reducing local plant diversity, changing soil biotic communities, and altering fire regimes (Dickie et al. 2014, Gundale et al. 2016, Taylor et al. 2016b, Franzese et al. 2017, Taylor et al. 2017).

We evaluated the direct impact of $P$. contorta on plant communities in its native vs non-native ranges; and further, evaluated whether its impact on native plant communities 
is more severe in the Southern Hemisphere where native species have little eco-evolutionary experience with species similar to P. contorta, than in Europe, where Pinus is not novel. Many studies have examined the impacts of invaders on plant communities in specific regions by comparing the diversity in invaded areas to adjacent uninvaded vegetation, but our global study has the unique ability to identify how impacts of an introduced invasive species vary across biogeographic regions. Given that alteration of the microenvironment (e.g. through increased canopy cover or litter accumulation) is an important mechanism of invader impact (Skurski, et al. 2014), we also determined whether differences in $P$. contorta growth rates or litter accumulation across sites explained variation in impact. We tested three hypotheses: 1) understory plant communities associated with $P$. contorta will be less species rich in its non-native range compared to its native range; 2) differences in species richness and composition between $P$. contorta stands and adjacent vegetation will be greater in areas where $P$. contorta is not native; 3 ) outside its native range, $P$. contorta will grow faster, accumulate more litter, and have greater impacts on plant communities in the Southern Hemisphere communities which have less eco-evolutionary experience with species similar to P. contorta than in European plant communities where Pinus is not novel.

\section{Material and Methods}

\section{Sampling sites}

Pinus contorta was originally introduced to Europe and the Southern Hemisphere in areas that were similar in climate, edaphic conditions, and latitude to source populations in western North America (Gundale et al. 2014b). We designed our study to take advantage of these native source-non-native destination regions and sampled a total of 53 sites (Fig. 1; see Gundale et al. 2016). Pinus contorta from British Columbia, Canada (CA; 7 sites) was introduced into our northern European sites in Scotland, Sweden, and Finland (EU; 15 sites). Pinus contorta from northwestern United States (US; 17 sites) was introduced into our Southern Hemisphere sites in Argentina, Chile and New Zealand (SH; 14 sites). Within each region, $P$. contorta sampling stands were selected where they were mono-dominant, even-aged, and between 15 and 125 yr old. In Europe and Canada, stands were chosen based on known locations of seed sources (see Gundale et al. 2016 for details). Precise locations of seed sources for the Southern Hemisphere stands are unknown, so sampling sites spanned a large part of the northwestern United States to capture the potential range of variability of the source populations (Gundale et al. 2014b). Details on sites are in Supplementary material Appendix 1 Table A1.

To examine differences in productivity and climate between sites, we compared climate for our source-destination pairs using the Mahalanobis distance (Mesgaran et al. 2014).

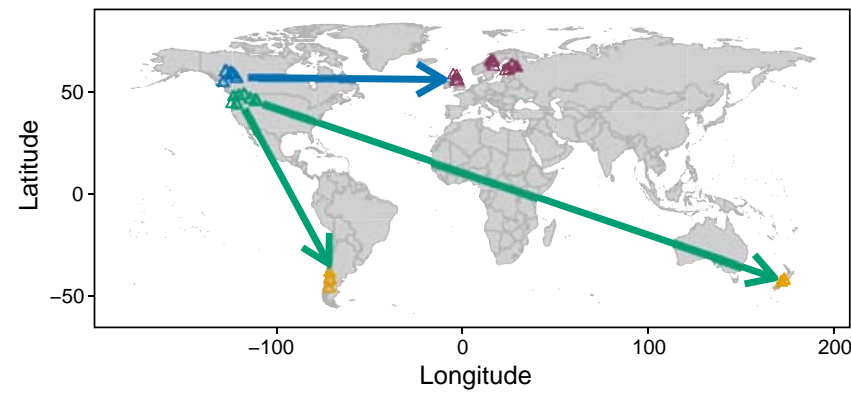

Figure 1. Map depicting study site locations $(n=53)$. Pinus contorta is native to the sites in North America. It was introduced to northern Europe from the sites in Canada and to the Southern Hemisphere from the western United States region where sites were sampled.

We compared climates using six bioclimatic variables: mean annual precipitation, mean annual temperature, precipitation of the wettest month, precipitation of the driest month, minimum temperature of the coldest month, and maximum temperature of the warmest month. Climate data for each site were extracted from $2.5 \mathrm{~min}$ resolution WorldClim 1.4 data layers (Hijmans et al. 2005). Sites within sourcedestination pairs had similar climates (Supplementary material Appendix 1 Fig. A1).

\section{Field sampling}

At each site, we sampled paired stands of $P$. contorta and adjacent native vegetation. Paired stands ranged from 20 to $300 \mathrm{~m}$ apart from each other. In the Southern Hemisphere, adjacent native vegetation consisted of native forest (e.g. Nothofagus spp., Araucaria araucana, or Fuscospora spp.; 4 sites) or grasslands or shrublands (10 sites); whereas in Europe native vegetation consisted of plantations of the native Pinus sylvestris (L.). In Canada and at ten of the United States sites, adjacent vegetation consisted of forests dominated by other conifer species, and in one case aspen (Populus tremuloides). At the remaining seven United States sites, adjacent vegetation consisted of open grasslands or shrublands to balance sites in the Southern Hemisphere that were dominated by these 'open' vegetation types. Pinus contorta stands consisted of naturally regenerated forest (US, CA), plantations (US, EU, SH), and naturalized or invasive stands (SH; Supplementary material Appendix 1 Table A1). All plantations were in their first rotation of Pinus contorta. In Europe, both native $P$. sylvestris and non-native $P$. contorta plantations received the same management regime. In Sweden and Finland this consisted of furrowing the soil before planting, and one pre-commercial thinning event between 10-20 yr of stand development. In Scotland plantations were cultivated prior to planting but were not thinned. Plantations in Argentina, Chile, New Zealand, and United States did not receive any management treatments beyond the initial planting. Despite these management differences across the study system, all stands shared a similar stand structure (i.e. monodominant and even-aged), thus serving as a powerful tool to 
compare the effects of $P$. contorta presence on plant communities across a wide range of environments.

At each site, ten $2 \times 2 \mathrm{~m}$ plots were randomly placed in both the $P$. contorta stand and the paired native vegetation. For simplicity, hereafter the term 'stand' is used for both forestdominated sites and for native vegetation dominated by grass or shrubs. Adjacent plots were between 3 and $50 \mathrm{~m}$ apart from each other. Within each plot the identity and percent cover of all vascular and non-vascular plants that were not overstory trees were recorded in standard relevé cover classes $(<1 \%$, $1-5 \%, 5-15 \%, 15-25 \%, 25-50 \%, 50-75 \%,>75 \%)$. Thus, species richness and composition of each plot in the statistical analysis excludes overstory canopy trees. We also estimated the basal area (BA) of the stand around each of the 10 plots using the point-sampling method and a basal area prism, or by measuring tree diameters. We measured the litter depth at the center of each plot (i.e. the Oi horizon that includes fresh litter inputs that are still recognizable as litter). In the P. contorta stands we identified the three individuals with the largest diameter at breast height $(\mathrm{DBH}, 1.35 \mathrm{~m})$ and measured the height and $\mathrm{DBH}$ of these individuals. Where the age of the stand was unknown (i.e. outside established plantations), we also cored these trees with increment borers to estimate approximate stand age. When rings were not clearly visible, standard dendrochronological techniques (Stokes and Smiley 1968) were used to prepare cores for examination under a stereomicroscope. We used the DBH divided by tree age to coarsely estimate mean $P$. contorta growth rates for the three largest trees in each stand.

\section{Statistical analysis}

For all statistical comparisons, individual stands served as the unit of replication, and thus any plot data within stands were averaged to create a stand value for each variable. To examine differences among $P$. contorta stands across regions we used three multiple linear regression models and ANCOVA to test for differences in three response variables between regions: mean species richness, litter depth, and growth rate in $P$. contorta stands. We included region, as well as stand $\mathrm{BA}$, stand age, and mean annual temperature or mean annual precipitation as covariates in each model to account for differences in productivity and climate among sites. Full models with each climate variable were conducted separately due to collinearity between mean annual temperature and precipitation. When these covariates were not related $(\mathrm{alpha}=0.05)$ to richness, litter depth or growth rate, they were not included in the final model. Pairwise comparisons between regions were examined using the package 'lsmeans' (Lenth 2016) and the Bonferroni correction was applied.

To examine how differences in species richness between $P$. contorta stands and adjacent vegetation varied by region, we calculated the difference in mean plot-level richness between paired $P$. contorta and non-P. contorta stands within the same site ( $\Delta$ Rich). Calculating $\Delta$ Rich for each site thus controlled for overall differences in species richness among sites. We used one-way analysis of variance (ANOVA) and post-hoc Tukey's tests to assess differences in $\triangle$ Rich among regions. To further examine potential explanations for the observed differences in $\Delta$ Rich between regions we used hierarchical partitioning of variance (Walsh and Mac Nally 2013) to determine the relative contribution of region, $\triangle \mathrm{BA}$, growth rate, stand age, adjacent vegetation type (open or forest), and litter depth in explaining the variance in $\Delta$ Rich among sites. Due to correlation between some variables (e.g. growth rate and region), we used hierarchical partitioning rather than multiple regression to alleviate the problems associated with collinearity (Chevan and Sutherland 1991). This method determines the independent contribution of each predictor variable to the response separately from the joint contribution, which results from correlations between predictors. $\triangle \mathrm{BA}$ is the difference in $\mathrm{BA}$ between paired stands in the same site (i.e. BA P. contorta BA native vegetation).

To examine stand scale differences in richness in each region, we used paired t-tests to determine if the total number of species per stand (10 plots combined, rather than plot-level means) differed between the P. contorta and non-P. contorta stands within sites. We adjusted p-values for multiple comparisons with the Bonferroni correction. We used ANOVA and post-hoc Tukey's tests to compare the magnitude of the difference in total species richness between $P$. contorta and non-P. contorta stands among regions. We also compared species accumulation rates between paired $P$. contorta and non-P. contorta stands with species accumulation curves.

To examine differences in species composition between $P$. contorta and non-P. contorta stands, we calculated the Gower similarity between plots, which includes both species composition and abundance based on the ordinal cover class data. We calculated the centroid of the 10 plots for each stand based on the Gower distance with the 'betadisper' function in R (Oksanen et al. 2013). We used permutational analysis of variance (PERMANOVA) based on the Euclidean distances between the centroids to test if the composition differed between $P$. contorta and non$P$. contorta stands across all sites, and if the magnitude of this difference varied by region, after accounting for variation due to site. We applied a principal coordinates analysis (PCoA) to graphically display differences in species composition between groups.

Finally, we tested if the beta-diversity differed between stand type and region. Differences in beta-diversity can be tested by comparing the homogeneity of multivariate dispersions between stands (Anderson et al. 2006). Beta-diversity is best calculated with just the presence and absence of species within stands, rather than including abundance (Anderson 2006), so we used Jaccard's dissimilarity to compare betadiversity between stand types and regions. All statistical analyses were conducted in R (R Core Team) and the species composition analysis was conducted with the 'vegan' package (Oksanen et al. 2013), with significant differences evaluated using alpha $=0.05$. 


\section{Data deposition}

Data available from the Dryad Digital Repository: <http:// dx.doi.org/10.5061/dryad.j574gb3 > (Davis et al. 2018).

\section{Results}

\section{Species richness, litter and growth rates between introduced and native $\mathbf{P}$. contorta stands}

Species richness was lower in the Southern Hemisphere than in the United States after accounting for mean annual temperature and stand basal area $(\mathrm{p}=0.010, \mathrm{t}=-3.33$, $\mathrm{df}=47$; Supplementary material Appendix 1 Table A2A4). However, there were no significant differences in richness among other regions (pairwise comparisons $\mathrm{p}>0.05$; Supplementary material Appendix 1 Table A4). Growth rate of $P$. contorta was significantly higher in the Southern Hemisphere than in any other region after accounting for stand age ( $\mathrm{p}<0.001$ for all pairwise comparisons; Supplementary material Appendix Table A2-A3), but did not vary among the other regions (Supplementary material Appendix 1 Table A4). Overall litter depth was similar between regions (Supplementary material Appendix 1 Fig. A2), however the relationship between litter depth and basal area differed among regions after accounting for mean annual temperature $\left(\mathrm{F}_{3,43}=6.36, \mathrm{p}=0.001\right.$; Supplementary material Appendix Table A3). Litter depth increased with basal area in the Southern Hemisphere, while it tended to decline with basal area in the other regions, although this pattern was less clear in Europe and the United States than in Canada (Supplementary material Appendix 1 Table A3, Fig. A2).

\section{Within-site species richness and composition}

Mean (SD) plot-level species richness in $P$. contorta vs nonP. contorta stands was 5.9 (3.3) vs 7.2 (3.0) in Europe, 8.3 (3.1) vs 8.5 (3.8) in Canada, 5.1 (3.2) vs 10.0 (4.0) in the Southern Hemisphere, and 8.8 (4.3) vs 8.9 (4.6) in the United States. The difference in mean richness ( $\triangle$ Rich) between paired stands within sites ( $P$. contorta - non- $P$. contorta) varied significantly among regions $\left(\mathrm{F}_{3,49}=14.74\right.$, $\mathrm{p}<0.001)$. The difference in richness between $P$. contorta stands and native stands was significantly more negative in the Southern Hemisphere than in all other regions; there were significantly fewer species in the $P$. contorta stands than in non-P. contorta stands ( $\mathrm{p}<0.001$ for all post-hoc pairwise comparisons). There were no significant differences among the other regions $(\mathrm{p}>0.05)$. There was variation in $\Delta$ Rich within regions, but overall the trends found at the regional level were consistent (Supplementary material Appendix 1 Fig. A3). Region independently explained more than twice as much variability in $\Delta$ Rich than any other explanatory variable (Fig. 2A). Adjacent vegetation type (open or forest), $P$. contorta growth rate, and $P$. contorta stand age explained additional variation in $\Delta$ Rich (Fig. 2). Differences in BA and litter depth explained little of the variability in $\Delta$ Rich.

Results for the total number of species per stand were similar to the plot-level results. The total number of species was lower in $P$. contorta stands than in non-P. contorta stands in both Europe and the Southern Hemisphere $(p=0.003$, $\mathrm{t}=4.31, \mathrm{df}=14 ; \mathrm{p}=0.005, \mathrm{t}=4.11, \mathrm{df}=13$, respectively), but not in Canada or the United States $(\mathrm{p}=1.00, \mathrm{t}=-0.47$, $\mathrm{df}=6 ; \mathrm{p}=1.00, \mathrm{t}=-0.20, \mathrm{df}=16$, respectively). The mean (SD) difference in total species between $P$. contorta and native stands within sites was 3.3 (3.0) species in Europe and 8.4 (7.6) species in the Southern Hemisphere. The magnitude of the difference in total species between the P. contorta and non- $P$. contorta stands at each site differed by region $\left(\mathrm{p}<0.001, \mathrm{~F}_{3,49}=7.07\right)$, with a significantly larger difference in SH than US ( $p<0.001$ ), but no difference between EU and CA $(p=0.29$; Supplementary material Appendix 1 Fig. A4). Species accumulation curves (Fig. 3; Supplementary material Appendix 1 Fig. A5-A12) show that at most sites sampling effort was sufficient to capture the majority of the species. Curves for $P$. contorta stands in the introduced range were most likely to saturate quickly, while some native stands were still accumulating species, suggesting that we may have underestimated differences between $P$. contorta and non$P$. contorta stands at some sites or differences between native and introduced stands of $P$. contorta (Fig. 3; Supplementary material Appendix 1 Fig. A5-A12).

Both stand type (P. contorta vs non- $P$. contorta; $\mathrm{F}_{1,50}=4.40$, $\mathrm{p}=0.001)$ and the interaction between region and stand type $\left(\mathrm{F}_{3,50}=2.63, \mathrm{p}=0.001\right)$ had significant effects on species composition. The PCoA analysis showed that composition varied more between $P$. contorta and non-P. contorta stands in the Southern Hemisphere than in any other region (Fig. 4). Beta-diversity also differed significantly among regions $\left(\mathrm{F}_{3,101}=31.58, \mathrm{p}<0.001\right)$, with lower beta-diversity in Europe and Canada than the Sothern Hemisphere and United States. However, within regions beta-diversity did not differ between $P$. contorta and non- $P$. contorta stands $(\mathrm{p}>0.05$ for all pairwise comparisons).

\section{Discussion}

Our results are consistent with the hypothesis that ecoevolutionary experience influences invasion impacts, with greater impacts where native species have less experience with species similar to the invader. This was demonstrated in two ways. First, and consistent with our first and third hypotheses, reductions in the diversity of understory vegetation in non-native (SH, EU) compared to native (US, CA) $P$. contorta stands were greater where native species had no experience with species similar to $P$. contorta. In particular, Southern Hemisphere (where there are no native Pinaceae) $P$. contorta stands had lower understory species richness than source sites in the United States. However, there was no difference in species richness in the understory of $P$. contorta 


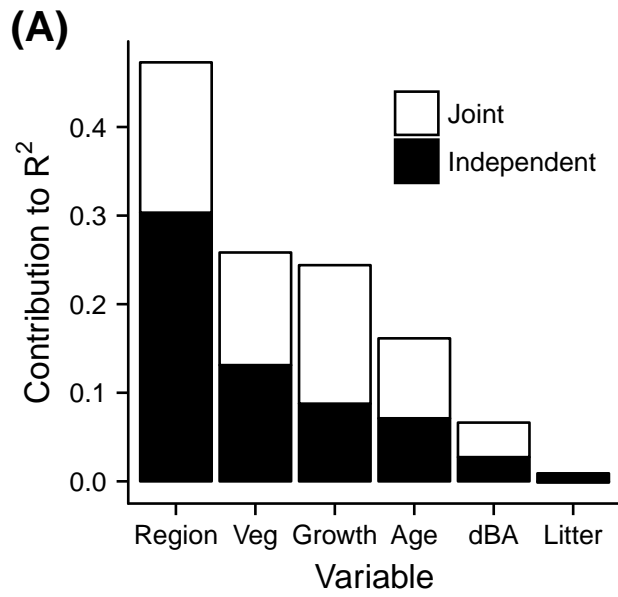

(C)

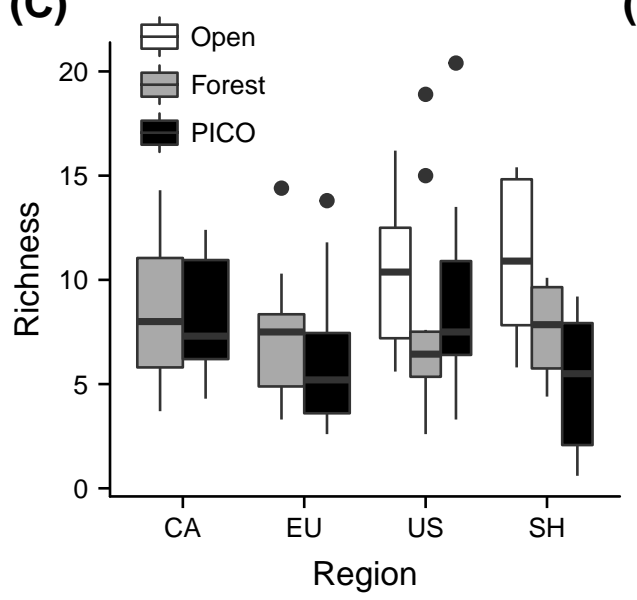

(B)

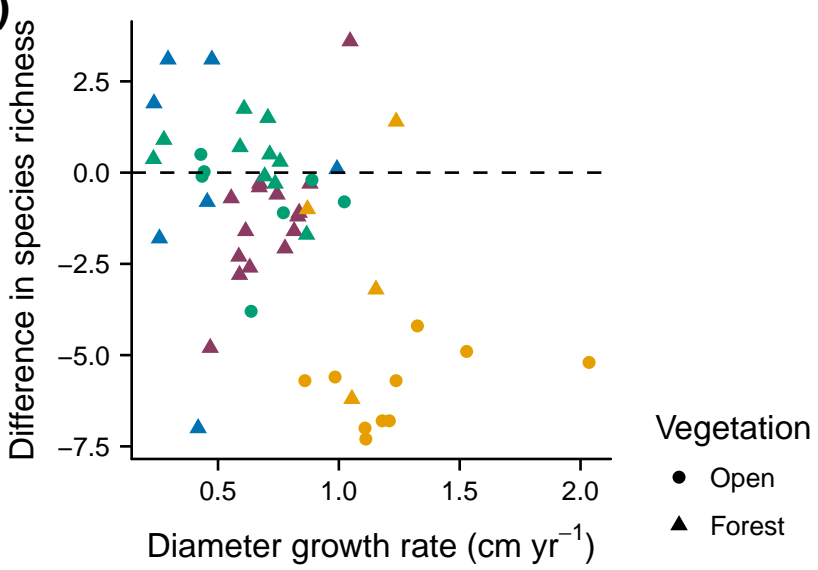

(D)

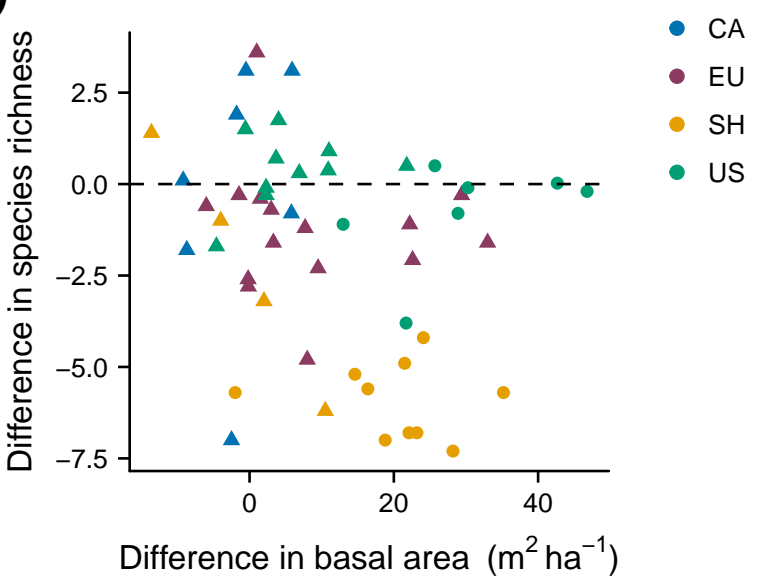

Figure 2. Contribution of each variable to explaining the variance in the difference in richness $(\triangle$ Rich) between $P$. contorta (PICO) and non- $P$. contorta vegetation within a site determined with hierarchical partitioning of variance (A), $\Delta$ Rich plotted against mean $P$. contorta growth rate (B) and mean difference in basal area (BA) between the P. contorta and non-P. contorta stands (dBA; D), and the distribution of species richness in each region across sites with different vegetation types (C). 'Joint' is variance explained jointly by multiple variables due to collinearity and 'Independent' is variance explained solely by that predictor. 'Veg' and 'vegetation' refer to whether the non-P. contorta vegetation was dominated by other tree species (forest) or by herbaceous and/or shrub species (open).

stands between Europe and the source region in Canada. Our models controlled for differences in climate and basal area between stands, indicating that declines in species richness in $P$. contorta stands were not simply related to regional differences in these factors (however see below for a discussion of management effects). Second, and consistent with our second and third hypotheses, reductions in plant species richness under $P$. contorta stands relative to under neighboring native vegetation were also greater where $P$. contorta was not native and more novel. Southern Hemisphere P. contorta stands were more species-poor than surrounding native vegetation, whereas there was no difference in species richness between European $P$. contorta stands and adjacent native forests when stands had the same basal area. Species composition also differed more between $P$. contorta and non-P. contorta stands in the Southern Hemisphere than in any other region.

Our findings are supported by a few local-scale studies of exotic conifer impact on biodiversity. For example, previous studies in Patagonia found that exotic conifer plantations were associated with lower native biodiversity than native forests (Paritsis and Aizen 2008, Fajardo and Gundale 2018). Naturalized stands were also found to have negative impacts on plant diversity at sites in New Zealand, Chile and Argentina (Ledgard and Paul 2008, Dickie et al. 2011, Taylor et al. 2016b, Franzese et al. 2017). In contrast, a study in Sweden showed that plant diversity in P. contorta plantations was similar to native $P$. sylvestris stands (Nilsson et al. 2008). Our results employing the same methodology across a wide range of introduced environments throughout Europe and the Southern Hemisphere support the hypothesis that eco-evolutionary experience is important in determining interactions between native and introduced species. Several studies have examined biological invasions in the context of Darwin's Naturalization Hypothesis (Rejmánek 1996, Daehler 2001, Duncan and Williams 2002). To our knowledge, our study is the first to quantify the impact of a species 

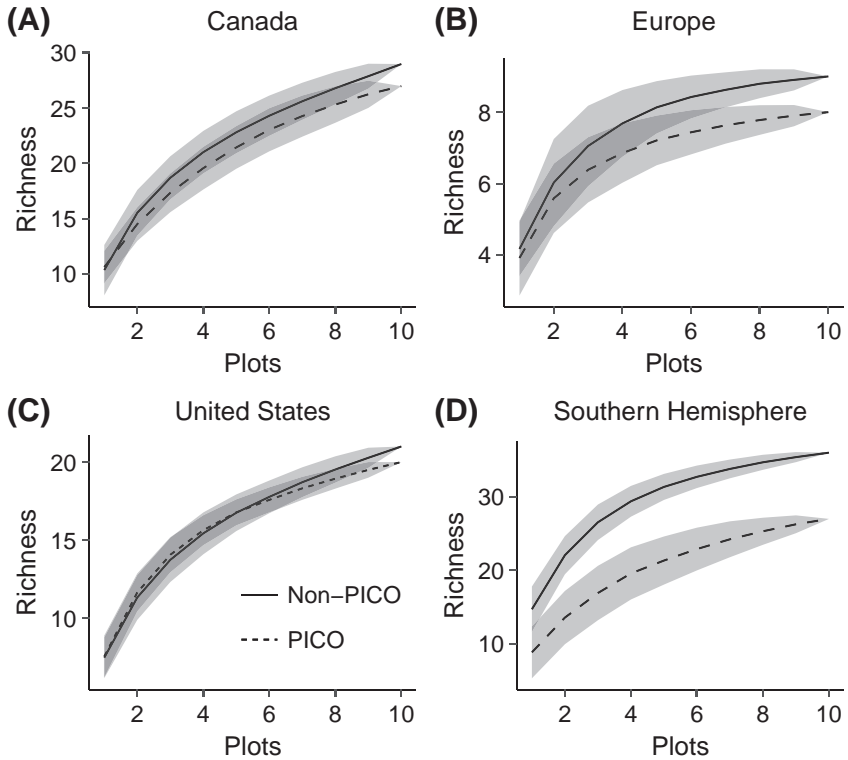

Figure 3. Species accumulation curves for $P$. contorta (PICO; dashed line) and non-P. contorta (Non-PICO; solid line) stands at representative sites from each region. Shaded area is one standard deviation calculated from random permutations of the data (subsampling without replacement; Gotelli and Colwell 2001). See Supplementary material Fig. A5-A12 for curves from all sites.

in terrestrial ecosystems across a wide range of native and exotic range sites, with and without native congeners (see Ricciardi and Atkinson (2004) for aquatic systems).

Aside from region, the most important factor explaining differences in species richness between $P$. contorta and adjacent vegetation was whether the native vegetation

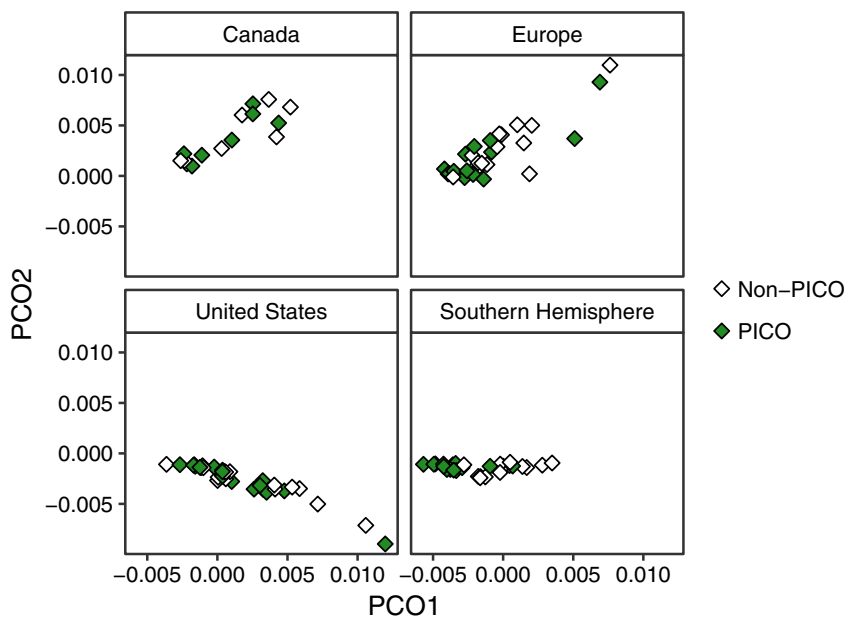

Figure 4. Principal coordinates analysis (PCoA) showing the results of the permutational analysis of variance (perMANOVA) testing differences in plant species composition based on Gower dissimilarity. The analysis was conducted for all sites combined but is displayed by region for improved clarity. Filled points represent $P$. contorta (PICO) stands and empty points represent non-P. contorta (non-PICO) stands. was a forest or an open habitat dominated by grasses or shrubs. Additionally, species composition differed most between $P$. contorta and adjacent vegetation in the Southern Hemisphere, where many of the sites were dominated by open habitat. These results suggest that the potential impacts of an invader are highest where that invader introduces a new life form, consistent with other studies (Franzese et al. 2017). Although some P. contorta stands in Europe had much higher basal area than the native stands, the effect on species richness was similar to when there was no difference in basal area (Fig. 2D) further highlighting the importance of the eco-evolutionary experience of the native plants. Species in the European sites are adapted to a forest environment, whereas many of the native species in the Southern Hemisphere open habitat types are not shade tolerant and thus decline with increasing canopy cover (Bravo-Monasterio et al. 2016, Taylor et al. 2016b). Open habitat types are also the least resistant to $P$. contorta invasion (Taylor et al. 2016a), thus the potential for both invasion and subsequent impacts may be highest in grassland and shrubland habitats. While differences in richness were more consistent in open habitat types, half of the Southern Hemisphere forest sites also had higher richness than the adjacent $P$. contorta stands, suggesting that mechanisms other than canopy cover may also affect species richness. Interestingly, there was no difference in species richness between open habitats and $P$. contorta stands in the United States (Fig. 2C). However, these sites likely had fairly stable vegetation types over long time periods. Where $P$. contorta has recently established into open habitats a similar decline in species richness was observed in both native and introduced ranges (Taylor et al. 2016b), supporting the idea that the eco-evolutionary experience of the receiving community is important, even within the native range.

Increased $P$. contorta growth rates were also associated with a larger difference in species richness between $P$. contorta stands and native vegetation. Some non-native species are known to attain greater individual sizes or population densities in their non-native ranges (Parker et al. 2013), which could potentially lead to greater total competitive effects on native vegetation. Other studies have also found faster $P$. contorta growth in the non-native range than in a native range (Taylor et al. 2016a) and in soil from the non-native compared to the native range (Gundale et al. 2014a). More rapid growth likely corresponds with more rapid canopy closure, light preemption and thus greater competitive effects on understory species. In drier sites, such as the Patagonian steppe, more rapid growth could also lead to more competition for limited soil moisture, but this possibility remains to be determined.

Region alone explained the most variability in impact between sites, suggesting that mechanisms beyond canopy cover and competition are also important in determining the effect of $P$. contorta on native vegetation. Variation in biochemical effects on other plants through allelopathy, alteration of soil biota, or changes in nutrient cycling have all been hypothesized as potential drivers of differences in 
invader impacts among biogeographic regions ( $\mathrm{Ni}$ et al. 2010, Kaur et al. 2012). Our results support the idea that such variation may be related to eco-evolutionary experience. Pines are well known for their effects on soil biota, soil chemistry and nutrient cycling (Scholes and Nowicki 1998, Gundale et al. 2016). The lack of differences in P. contorta impact between Europe and Canada may be due to the fact that understory forest species in Europe are adapted to the biochemical effects of closely related pine species (e.g. Pinus sylvestris) and some understory species are shared between the two regions. There are some differences in litter production and composition between plantations of $P$. sylvestris and $P$. contorta, but relatively little difference in belowground properties such as soil carbon, nutrient stocks, active microbial biomass, associated fungal communities, and pH (Ågren and Knecht 2001, McIntosh et al. 2012). On the other hand, outside the native distribution of the Pinaceae in our Southern Hemisphere sites where forests are often dominated by broad-leaved species, the stronger apparent suppression of species richness by $P$. contorta could be driven by different biogeochemical effects compared to native communities. Although litter depth was not important, differences in the chemical composition of the litter between $P$. contorta and native vegetation could have cascading effects on nutrient cycling and biota. In fact, belowground properties tend to differ between $P$. contorta stands and native forests in the Southern Hemisphere. For example, in Chile native Nothofagus pumilio forests have higher stocks of organic matter, $\mathrm{C}, \mathrm{N}$ and $\mathrm{P}$ than P. contorta plantations (Fajardo and Gundale 2015). Similarly, in New Zealand, soil organic matter, microbial biomass, and abundance and diversity of nematodes are all higher under the native Nothofagus solandri var. cliffortiodes compared to P. contorta stands (Dehlin et al. 2008). Fungal communities associated with $P$. contorta differ strongly from fungal communities associated with native forest in both Chile and New Zealand (Gundale et al. 2016). At the sites where P. contorta was introduced to grassland or shrubland systems, the concomitant introduction of their ectomycorrhizal mutualists may cause shifts in nutrient cycling in these systems previously dominated by arbuscular mycorrhizal associations (Chen et al. 2008, Dickie et al. 2014, Nuñez and Dickie 2014). These changes in nutrient cycling and soil biota likely contribute to the effects on plant diversity that we observed.

The global design of our study imposed certain limitations. For example, $P$. contorta stands varied somewhat in management history (e.g. plantation vs naturally regenerated). While exotic tree plantations can have lower plant diversity than natural forests (Paritsis and Aizen 2008), this effect varies with plantation age, management intensity, and similarity in tree species composition and structure between plantations and natural forests (Brockerhoff et al. 2008, Bremer and Farley 2010). The majority of the plantations we sampled were fairly young (median age $29 \mathrm{yr}$ ), in their first $P$. contorta rotation and received minimal or no management following planting. Furthermore, the native P. contorta forests in North America were also monodominant and similar in structure to plantations. If there were a large negative effect of plantation management on understory plant communities, we would expect to find the lowest species richness in P. contorta stands in Europe where all the stands were plantations; however, these plantations did not differ in species richness from natural forests in Canada. Comparisons between P. contorta stands and adjacent vegetation may also have been affected by management history. However, this could not have introduced any bias in our comparisons between P. contorta and P. sylvestris in Europe, because they all experienced the same management. It is possible that the lower richness found in P. contorta stands in the Southern Hemisphere compared to the United States could partially be due to the higher proportion of plantations sampled in the Southern Hemisphere compared to North America (i.e. $36 \%$ vs $12 \%$, respectively). However, there was no significant difference in richness between naturalized $P$. contorta stands and $P$. contorta plantations in the Southern Hemisphere $(p=0.08, t=1.94$, $\mathrm{df}=11$ ), particularly in South America where more plantations were sampled (Supplementary material Appendix 1 Fig. A13). Thus, it is unlikely that these historical differences had a large impact on our findings. It is also possible that the difference in $P$. contorta source populations from which trees were introduced to Europe (from Canada) and the Southern Hemisphere (from the United States) may contribute to some of the variability in impact observed between these two regions due to high levels of intraspecific variability in $P$. contorta.

The time since pine introduction may have influenced our results given that the impacts of exotic species on native communities can decline over time (Strayer et al. 2006). However, most study regions have a similar introduction history. Pinus contorta or other conifers were introduced in a limited way in the late 19th and early 20th century. Largescale planting of $P$. contorta did not occur until the 1960's to 1970's in all regions, except Scotland where widespread use began earlier around 1945 and in Chile where commercial use became more widespread in the 1980's (Lines 1996, Elfving et al. 2001, Ledgard 2001, Simberloff et al. 2010, Savill 2013, Ruotsalainen 2017). Thus, it is possible that the difference in impacts between Scotland and Chile are partially related to time since introduction. Although, the difference in species richness between $P$. contorta and non- $P$. contorta stands was less in Chile than in the other Southern Hemisphere countries where $P$. contorta was planted widely about 10 to $20 \mathrm{yr}$ earlier (Supplementary material Appendix Fig. A3).

The impacts of non-native invasive species have been well studied worldwide, but it has only recently been recognized that these impacts vary strongly among species and are often context-dependent (Pyšek et al. 2012, Kumschick et al. 2015). Our global study demonstrates that eco-evolutionary experience can help to predict the magnitude of invader impacts on biodiversity across regions having different evolutionary histories. Although hypothesized previously (Saul and Jeschke 2015), to our knowledge our study is the first to empirically test this hypothesis for an invasive plant across a wide range of introduced and native sites that span 
a large biogeographic range. We found consistently different responses to $P$. contorta dominance between Europe (congenerics present) and the Southern Hemisphere (congenerics absent). Understanding how the evolutionary context affects the likelihood of invader impacts should help to prioritize invasive species management (Blackburn et al. 2014), and demonstrates the importance of ecological and evolutionary context in determining plant community dynamics.

Acknowledgements - We thank Stephen Brewer for assistance with the species composition analysis. We also thank Pablo BravoMonasterio (Chile) for help with fieldwork and species recognition. Funding - ACSM was funded by Univ. of Alberta start-up grant. AF was funded by Fondecyt project 1120171. AP was funded by ICM P05-002, PFB-23 and Fondecyt 1140485. BDM and KTD were funded by NSF-WildFIRE PIRE, OISE 09667472. MJG was funded by the Swedish Research Council VR (201603819). MN was funded by Bio \# 5 GEF 090118 and MN and RDD were funded by PICT project no. 0662. RMC thanks the National Science Foundation Experimental Program to Stimulate Competitive Research Track-1 EPS-1101342 (INSTEP 3) for support. The Scottish sites were funded through UK Forest Research's Long-Term Experiments Work Package. RWB and RJP were supported by the Rural and Environment Science and Analytical Services Division of the Scottish Government through the Strategic Research Programmes 2011-2016 and 2016-2021.

\section{References}

Ågren, G. I. and Knecht, R. E. 2001. Simulation of soil carbon and nutrient development under Pinus sylvestris and Pinus contorta. - For. Ecol. Manage. 141: 117-129.

Anderson, M. J. 2006. Distance-based tests for homogeneity of multivariate dispersions. - Biometrics 62: 245-253.

Anderson, M. J. et al. 2006. Multivariate dispersion as a measure of beta diversity. - Ecol. Lett. 9: 683-693.

Bennett, J. A. et al. 2014. Patterns of phylogenetic diversity are linked to invasion impacts, not invasion resistance, in a native grassland. - J. Veg. Sci. 25: 1315-1326.

Blackburn, T. M. et al. 2014. A unified classification of alien species based on the magnitude of their environmental impacts. - PLoS Biol. 12: e1001850.

Bravo-Monasterio, P. et al. 2016. Pinus contorta invasion into treeless steppe reduces species richness and alters species traits of the local community. - Biol. Invasions 18: 1883-1894.

Bremer, L. L. and Farley, K. A. 2010. Does plantation forestry restore biodiversity or create green deserts? A synthesis of the effects of land-use transitions on plant species richness. - Biodivers. Conserv. 19: 3893-3915.

Brewer J. S. et al. 2018. Impact of invasive slash pine (Pinus elliottii) on groundcover vegetation at home and abroad. - Biol. Invasions doi:10.1007/s10530-018-1734-z.

Brockerhoff, E. G. et al. 2008. Plantation forests and biodiversity: oxymoron or opportunity? - Biodivers. Conserv. 17: 925-951.

Callaway, R. M. and Aschehoug, E. T. 2000. Invasive plants versus their new and old neighbors: a mechanism for exotic invasion. - Science 290: 521-523.
Callaway, R. M. and Ridenour, W. M. 2004. Novel weapons: invasive success and the evolution of increased competitive ability. - Front. Ecol. Environ. 2: 436-443.

Callaway, R. M. et al. 2012. Impact of Acroptilon repens on co-occurring native plants is greater in the invader's non-native range. - Biol. Invasions 14: 1143-1155.

Castro-Diez, P. et al. 2014. What explains variation in the impacts of exotic plant invasions on the nitrogen cycle? A meta-analysis. - Ecol. Lett. 17: 1-12.

Chen, C. R. et al. 2008. Impacts of grassland afforestation with coniferous trees on soil phosphorus dynamics and associated microbial processes: a review. - For. Ecol. Manage. 255: 396-409.

Chevan, A. and Sutherland M. 1991. Hierarchical Partitioning. - Am. Stat. 45:90-96.

Daehler, C. C. 2001. Darwin's naturalization hypothesis revisited. - Am. Nat. 158: 324-330.

Darwin, C. 1859. The origin of species. - J. Murray.

Davis, K. T. et al. 2018. Data from: Severity of impacts of an introduced species corresponds with regional eco-evolutionary experience. - Dryad Digital Repository, <http://dx.doi. org/10.5061/dryad.j574gb3>.

Dehlin, H. et al. 2008. Tree seedling performance and belowground properties in stands of invasive and native tree species. - N. Z. J. Ecol. 32: 67-79.

Dickie, I. A. et al. 2011. Ecosystem service and biodiversity tradeoffs in two woody successions. - J. Appl. Ecol. 48: 926-934.

Dickie, I. A. et al. 2014. Belowground legacies of Pinus contorta invasion and removal result in multiple mechanisms of invasional meltdown. - AoB Plants 6: plu056.

Diez, J. M. et al. 2008. Darwin's naturalization conundrum: dissecting taxonomic patterns of species invasions. - Ecol. Lett. 11: 674-681.

Duncan, R. P. and Williams, P. A. 2002. Ecology - Darwin's naturalization hypothesis challenged. - Nature 417: 608-609.

Elfving, B. et al. 2001. The introduction of lodgepole pine for wood production in Sweden - a review. - For. Ecol. Manage. 141: 15-29.

Engelmark, O. et al. 2001. Ecological effects and management aspects of an exotic tree species: the case of lodgepole pine in Sweden. - For. Ecol. Manage. 141: 3-13.

Fajardo, A. and Gundale, M. J. 2015. Combined effects of anthropogenic fires and land-use change on soil properties and processes in Patagonia, Chile. - For. Ecol. Manage. 357: 60-67.

Fajardo, A. and Gundale, M. J. 2018. Canopy cover type, and not fine-scale resource availability, explains native and exotic species richness in a landscape affected by anthropogenic fires and posterior land-use change. - Biol. Invasions. 20: 385-398.

Franzese, J. et al. 2017. Pine invasion impacts on plant diversity in Patagonia: invader size and invaded habitat matter. - Biol. Invasions 19: 1015-1027.

Gazol, A. et al. 2016. Impact of alien pines on local arbuscular mycorrhizal fungal communities - evidence from two continents. - FEMS Microbiol. Ecol. 92: fiw073.

Gotelli, N. J. and Colwell, R. K. 2001. Quantifying biodiversity: procedures and pitfalls in measurement and comparison of species richness. - Ecol. Lett. 4: 379-391.

Gundale, M. J. et al. 2014a. Interactions with soil biota shift from negative to positive when a tree species is moved outside its native range. - New Phytol. 2: 415-421. 
Gundale, M. J. et al. 2014b. Can model species be used to advance the field of invasion ecology? - Biol. Invasions 16: 591-607.

Gundale, M. J. et al. 2016. Differences in endophyte communities of introduced trees depend on the phylogenetic relatedness of the receiving forest. - J. Ecol. 104: 1219-1232.

Hejda, M. et al. 2017. Dominance has a biogeographical component: do plants tend to exert stronger impacts in their invaded rather than native range? - J. Biogeogr. 44: 18-27.

Hierro, J. L. et al. 2005. A biogeographical approach to plant invasions: the importance of studying exotics in their introduced and native range. - J. Ecol. 93: 5-15.

Hijmans, R. J. et al. 2005. Very high resolution interpolated climate surfaces for global land areas. - Int. J. Climatol. 25: 1965-1978.

Hulme, P. E. et al. 2013. Bias and error in understanding plant invasion impacts. - Trends Ecol. Evol. 28: 212-218.

Kaur, R., et al. 2012. Community Impacts of Prosopis juliflora Invasion: biogeographic and congeneric comparisons. - PLoS One 7: e44966.

Keane, R. M. and Crawley, M. J. 2002. Exotic plant invasions and the enemy release hypothesis. - Trends Ecol. Evol. 17: 164-170.

Kumschick, S. et al. 2015. Ecological impacts of alien species: quantification, scope, caveats, and recommendations. - Bioscience 65: 55-63.

Langdon, B. et al. 2010. Pinus contorta invasion in the Chilean Patagonia: local patterns in a global context. - Biol. Invasions 12: 3961-3971.

Ledgard, N. 2001. The spread of lodgepole pine (Pinus contorta, Dougl.) in New Zealand. - For. Ecol. Manage. 141: 43-57.

Ledgard, N. J. and Paul, T. S. H. 2008. Vegetation successions over 30 years of high country grassland invasion by Pinus contorta. - N. Z. Plant Prot. 61: 98-104.

Ledger, K. J. et al. 2015. Impact of an invader on species diversity is stronger in the non-native range than in the native range. - Plant Ecol. 216: 1285-1295.

Lenth, R. V. 2016. Least-squares means: the R package lsmeans. - J. Stat. Softw. 69: 1-33.

Leslie, A. B. et al. 2012. Hemisphere-scale differences in conifer evolutionary dynamics. - Proc. Natl Acad. Sci. USA 109: $16217-16221$.

Levine, J. M. et al. 2003. Mechanisms underlying the impacts of exotic plant invasions. - Proc. R. Soc. B 270: 775-781.

Li, S. P. et al. 2015. The effects of phylogenetic relatedness on invasion success and impact: deconstructing Darwin's naturalisation conundrum. - Ecol. Lett. 18: 1285-1292.

Lines, R. 1996. Experiments on lodgepole pine seed origins in Britain. Forestry Commission Technical Paper 10. - Forestry Commission Edinburgh.

McIntosh, A. C. S. et al. 2012. Tree species versus regional controls on ecosystem properties and processes: an example using introduced Pinus contorta in Swedish boreal forests. - Can. J. For. Res. 42: 1228-1238.

Mesgaran, M. B. et al. 2014. Here be dragons: a tool for quantifying novelty due to covariate range and correlation change when projecting species distribution models. - Divers. Distrib. 20: 1147-1159.

Ni, G.-Y. et al. 2010. Acroptilon repens, an Asian invader, has stronger competitive effects on species from America than species from its native range. - Biol. Invasions 12: 3653-3663.

Nilsson, C. et al. 2008. Differences in litter cover and understorey flora between stands of introduced lodgepole pine and native scots pine in Sweden. - For. Ecol. Manage. 255: 1900-1905.

Nuñez, M. A. and Dickie, I. A. 2014. Invasive belowground mutualists of woody plants. - Biol. Invasions 16: 645-661.

Nuñez, M. A. et al. 2017. Ecology and management of invasive Pinaceae around the world: progress and challenges. - Biol. Invasions. 19: 3099-3120.

Oksanen, J. et al. 2013. vegan: community ecology package. - In: $\mathrm{R}$ package ver. 2.0-10, <http:/CRAN.R-project.org/ package $=$ vegan $>$.

Paritsis, J. and Aizen, M. A. 2008. Effects of exotic conifer plantations on the biodiversity of understory plants, epigeal beetles and birds in Nothofagus dombeyi forests. - For. Ecol. Manage. 255: $1575-1583$.

Parker, J. D. et al. 2013. Do invasive species perform better in their new ranges? - Ecology 94: 985-994.

Proches, S. et al. 2008. Searching for phylogenetic pattern in biological invasions. - Global Ecol. Biogeogr. 17: 5-10.

Pyšek, P. et al. 2012. A global assessment of invasive plant impacts on resident species, communities and ecosystems: the interaction of impact measures, invading species' traits and environment. - Global Change Biol. 18: 1725-1737.

Qin, R. M. et al. 2013. The evolution of increased competitive ability, innate competitive advantages, and novel biochemical weapons act in concert for a tropical invader. - New Phytol. 197: 979-988.

Rejmánek, M. 1996. A theory of seed plant invasiveness: the first sketch. - Biol. Conserv. 78: 171-181.

Rejmánek, M. and Richardson, D. M. 2013. Trees and shrubs as invasive alien species - 2013 update of the global database. - Divers. Distrib. 19: 1093-1094.

Ricciardi, A. and Atkinson, S. K. 2004. Distinctiveness magnifies the impact of biological invaders in aquatic ecosystems. - Ecol. Lett. 7: 781-784.

Rundel, P. W. et al. 2014. Tree invasions into treeless areas: mechanisms and ecosystem processes. - Biol. Invasions 16: 663-675.

Ruotsalainen, S. 2017. The history of cultivation of exotic tree species in Finland. Natural resources and bioeconomy studies 88/2017. - Natural Resources Inst. Finland.

Savill, P. 2013. The silviculture of trees used in British forestry. - CABI.

Saul, W. C. et al. 2013. The role of eco-evolutionary experience in invasion success. - NeoBiota 17: 57-74.

Saul, W. C. and Jeschke, J. M. 2015. Eco-evolutionary experience in novel species interactions. - Ecol. Lett. 18: 236-245.

Scholes, M. C. and Nowicki, T. E. 1998. Effects of pines on soil properties and processes. - In: Richardson, D. M. (ed.) The ecology and biogeography of Pinus. Cambridge Univ. Press, pp. 341-380.

Shah, M. A. et al. 2014. Conyza canadensis suppresses plant diversity in its nonnative ranges but not at home: a transcontinental comparison. - New Phytol. 202: 1286-1296.

Simberloff, D. et al. 2010. Spread and impact of introduced conifers in South America: lessons from other southern hemisphere regions. - Austral Ecol. 35: 489-504.

Skurski, T. C. et al. 2014. Mechanisms underlying nonindigenous plant impacts: a review of recent experimental research. - Invasive Plant Sci. Manag. 7: 432-444.

Stokes, M. A. and Smiley, T. L. 1968. Tree-ring dating. - Univ. of Chicago Press. 
Strayer, D. L. et al. 2006. Understanding the long-term effects of species invasions. - Trends Ecol. Evol. 21: 645-651.

Taylor, K. T. et al. 2016a. Drivers of plant invasion vary globally: evidence from pine invasions within six ecoregions. - Global Ecol. Biogeogr. 25: 96-106.

Taylor, K. T. et al. 2016b. Native versus non-native invasions: similarities and differences in the biodiversity impacts of Pinus contorta in introduced and native ranges. - Divers. Distrib. 22: $578-588$

Supplementary material (Appendix ECOG-04014 at <www. ecography.org/appendix/ecog-04014>). Appendix 1.
Taylor, K. T. et al. 2017. Pinus contorta invasions increase wildfire fuel loads and may create a positive feedback with fire. - Ecology 98: 678-687.

Vilà, M. et al. 2006. Local and regional assessments of the impacts of plant invaders on vegetation structure and soil properties of Mediterranean islands. - J. Biogeogr. 33: 853-861.

Walsh, C. and Mac Nally, R. 2013. hier.part: hierarchical partitioning. - In: $\mathrm{R}$ package ver. 1.0-4, <https://cran.r-project.org/ web/packages/hier.part/index.html $>$. 